\title{
A network analysis of COVID-19 mRNA vaccine patents
}

A preliminary network analysis highlights the complex intellectual property landscape behind mRNA-based COVID-19 vaccines.

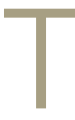

he COVID-19 pandemic has had a substantial impact on global health and highlighted the importance of international cooperation to effectively combat SARS-CoV-2. Since the discovery and publication of the virus's genome in January 2020, scientists have rushed to develop vaccines, therapeutics and diagnostics on an unprecedented timescale. To date there are 80 vaccines in clinical trials and 70 more in clinical development, setting the stage for some of the fastest vaccine development and testing in modern history ${ }^{1}$. The vaccine technology platforms used by the most promising vaccine candidates range from viral vector-based and protein-based technologies to mRNA and lipid nanoparticle technology. Despite these impressive scientific achievements, barriers such as the vaccine cold chain and multiple forms of intellectual property (IP) protection stand in the way of equitable access and fair allocation.

Webs of intellectual property claims underpin the marketing of many vaccines. For example, the underlying technology used to develop a vaccine can be protected by patents, while manufacturing methods and techniques (know-how) can be protected by trade secrets. Therapeutic development programs tend to consist of an intricate relationship between an inventor and an innovator ${ }^{2}$. The foundational technology needed to develop a vaccine could have been invented in an academic lab setting or startup research firm, protected through patents, and subsequently licensed out to a larger entity for further development and commercialization. These larger entities are designated as innovators because they transform the foundational technology into the final market product.

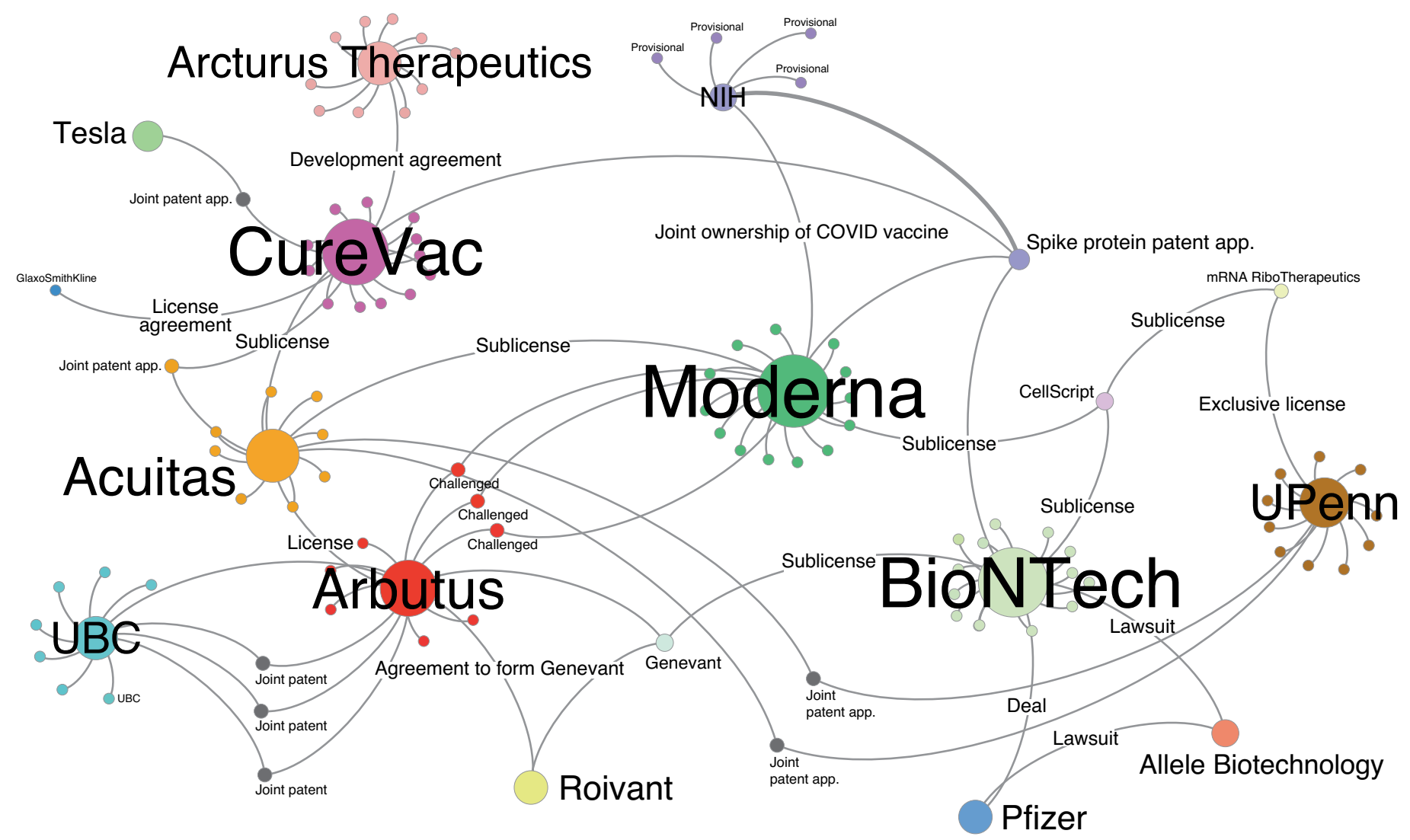

Fig. 1| Patent network analysis of mRNA-based vaccine candidates for COVID-19. Large nodes represent the relevant entities while the edges represent agreements or patents between two entities. Smaller nodes around the entities represent patents that were identified as being relevant to the underlying vaccine technology (Supplementary Information). The network analysis was developed using Gephi ${ }^{23}$. UPenn, University of Pennsylvania; UBC, University of British Columbia; app., application. 


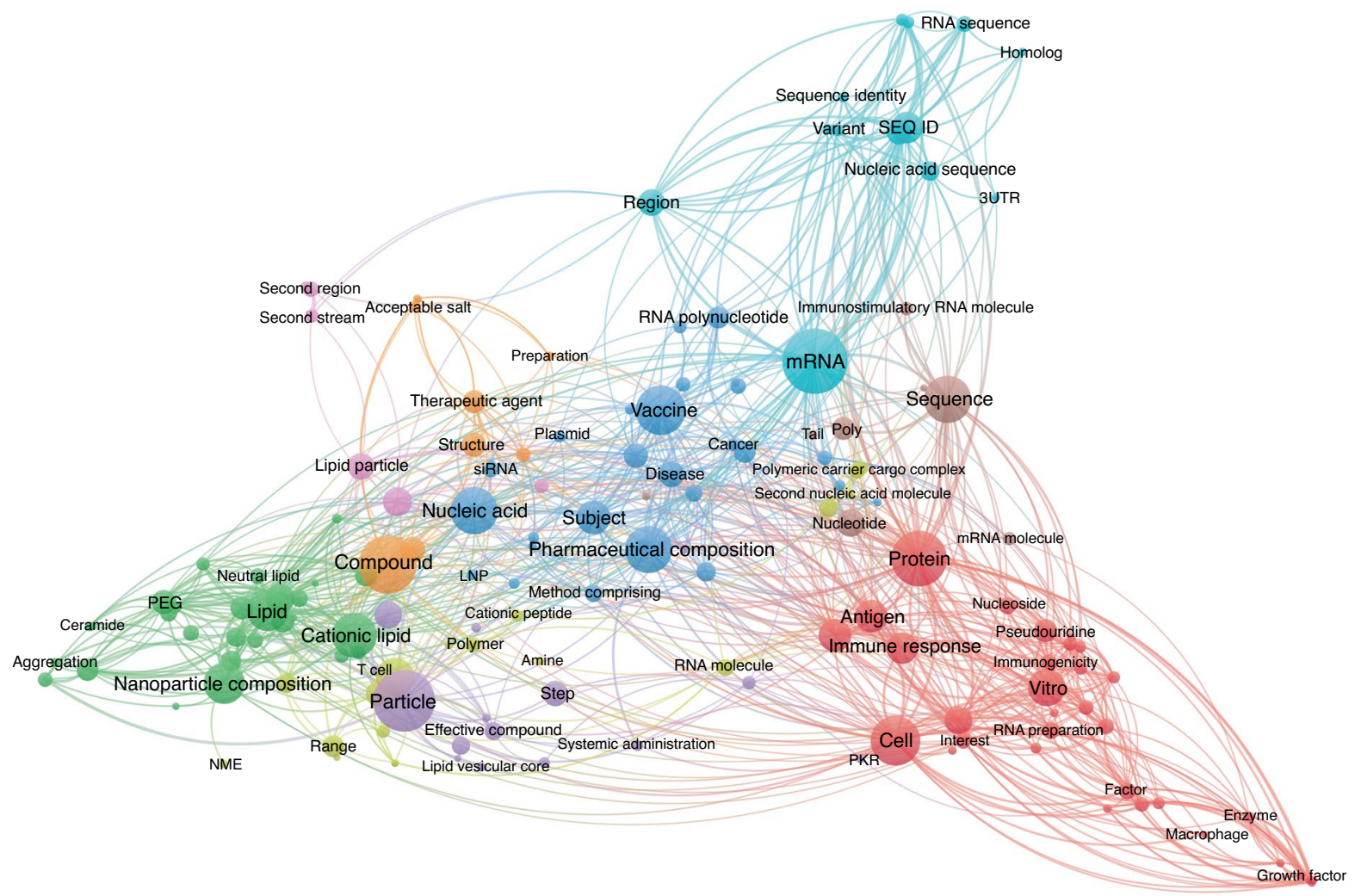

Fig. 2 | Landscape of scientific terms found in all of the abstracts and claims of the patents and applications that were identified as relevant to mRNA vaccine technology. The scientific landscape was developed using VOS Viewer. LNP, lipid nanoparticle; NME, new molecular entity; PEG, polyethylene glycol; PKR, protein kinase R; SEQ ID, sequence identifier; $3 U T R$, 3' untranslated region.

In an attempt to demonstrate the complexity involved in IP protections and licensing deals surrounding COVID-19 vaccine technology, we developed a preliminary patent network analysis. We identified patents that were relevant to various vaccine technology platforms and used US Securities and Exchange Commission (SEC) filings to highlight pertinent licensing deals. A visualization of the landscape is shown in Fig. 1.

Moderna, Pfizer and BioNTech, CureVac and Arcturus have all developed mRNA-based vaccine candidates for COVID-19. This vaccine technology platform uses mRNA technology, lipid nanoparticle technology and delivery system technology to achieve a desired biological response. A lipid nanoparticle must be used to deliver the mRNA to the cells to avoid mRNA degradation, which makes it a key aspect of the vaccine's technology. After the mRNA is delivered to a cell, it instructs the cell to produce the SARS-CoV-2 spike protein, thereby eliciting an immune response $\mathrm{e}^{3,4}$.

Scientists have studied the use of mRNA as a novel therapeutic since the early $1990 \mathrm{~s}^{5}$. However, it wasn't until 2005 that a group of researchers at the University of Pennsylvania published findings on mRNA technology that have since been deemed critical to the development of mRNA based therapies ${ }^{6}$. SEC filings highlighted by Knowledge Ecology International reveal a series of sublicenses for mRNA-related patents that stem from the University of Pennsylvania to both Moderna and BioNTech ${ }^{7-9}$. The 2017 filings indicate that the University of Pennsylvania exclusively licensed their patents to mRNA RiboTherapeutics, which then sublicensed them to its affiliate CellScript. CellScript proceeded to sublicense the patents to Moderna and BioNTech; however, the patent numbers are redacted in all the filings, making it difficult to determine which are relevant to the production of COVID-19 vaccines.

Another key aspect of an mRNA vaccine platform is the ability to deliver the mRNA to a cell using a lipid nanoparticle. Some early work on lipid nanoparticles was done jointly by the University of British Columbia and Arbutus Biopharmaceuticals in 1998. SEC filings show that patents relating to this early technology were solely assigned to the University of British Columbia and then licensed back to Arbutus ${ }^{10}$.
Further analysis reveals that in 2012 Arbutus licensed a set of patents relating to the delivery of nucleic acids to Acuitas Therapeutics. In 2016, Acuitas entered into a development and option agreement with CureVac, which included access to patents on lipid nanoparticle technology ${ }^{11}$. Acuitas also granted a sublicense to Moderna; however, in 2016 Arbutus declared that Acuitas's sublicense to Moderna was improper and took to the Canadian legal system for remedy ${ }^{10}$. The litigation in Canada was eventually settled, but in 2018 Moderna began filing inter partes reviews (IPR), a procedure for challenging the validity of a US patent before the US Patent and Trademark Office, on three of Arbutus's patents, which concluded with the cancellation of claims in two of the three challenges ${ }^{12}$. Moreover, Arbutus also entered into an agreement with Roivant to spin out Genevant, which received a license for the patent portfolio on lipid nanoparticles ${ }^{13}$. Genevant sublicensed the patents to BioNTech, who then entered into an agreement with Pfizer to develop a COVID-19 vaccine v $^{14-16}$. It is also important to note that the US National Institutes of Health (NIH) and Moderna entered 
into an agreement in 2019 to co-develop coronavirus vaccines; however, this was before the identification and spread of SARS-CoV-2 ${ }^{17,18}$.

The mRNA vaccine platform for COVID-19 relies on the production of the coronavirus spike protein to elicit an immune response. Moderna, CureVac, Pfizer and BioNTech have all disclosed that the mRNA used in their vaccine candidates encodes a stabilized version of the spike protein that was developed by the NIH. A report by Public Citizen identified a pending patent application on this modified spike protein that was filed by the $\mathrm{NIH}^{19}$. The NIH also has four other provisional patent applications on a novel coronavirus vaccine as disclosed in a recent publication ${ }^{17}$. This complex matrix of patents, licenses and agreements between these entities highlights the intricacies involved in biopharmaceutical development. Since patent numbers are redacted in all the SEC filings, we decided to develop our own patent landscape for the respective entities. Patents and patent applications that are relevant to the respective vaccine technology platform and owned or assigned to any of the entities discussed were identified and highlighted (Supplementary Information $)^{20,21}$. A visual representation of the science encompassed in the patents and applications is shown in Fig. $2^{22}$.

The success of mRNA vaccines in clinical trials highlights the potential of mRNA technology to be the future of medicine. The rapid development and clinical success of COVID-19 mRNA vaccines can be credited to the relationship between inventors and innovators. As evidenced by our network analysis, key technological advancements were invented in academic labs or small biotech companies and then licensed to larger companies for product development. Despite this success, patents, trade secrets and know-how owned by or assigned to larger companies may impede future research and development of mRNA technology by creating legal barriers that limit access to this technology.

\section{Mario Gaviria ${ }^{1 凶}$ and Burcu Kilic ${ }^{2}$}

${ }^{1}$ Department of Chemistry, University of Michigan, Ann Arbor, MI, USA. ${ }^{2}$ Public Citizen, Washington, DC, USA.

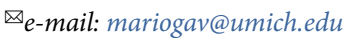

Published online: 12 May 2021

https://doi.org/10.1038/s41587-021-00912-9

References

1. Zimmer, C., Corum, J. \& Wee, S.-L. Coronavirus vaccine tracker The New York Times https://www.nytimes.com/interactive/2020/ science/coronavirus-vaccine-tracker.html (2020).

2. Kiliç, B. Boosting Pharmaceutical Innovation in the Post-TRIPS Era (Edward Elgar Publishing, 2014).

3. Walsh, E. E. et al. N. Engl. J. Med. 383, 2439-2450 (2020).

4. Corbett, K. S. et al. Nature 586, 567-571 (2020).

5. Wolff, J. A. et al. Science 247, 1465-1468 (1990).

6. Karikó, K., Buckstein, M., Ni, H. \& Weissman, D. Immunity 23, 165-175 (2005)

7. Abinader, L. G. Foundational mRNA patents are subject to the Bayh-Dole Act provisions. Knowledge Ecology International https://www.keionline.org/34733 (2020).

8. CellScipt \& Moderna. Patent sublicense agreement. EX-10.8. https://www.sec.gov/Archives/edgar/data/1682852/ 000119312518323562/d577473dex108.htm (2017).

9. CellScipt \& BioNTech. Patent sublicense agreement. EX-10.15 https://www.sec.gov/Archives/edgar/data/1776985/ 000119312519241112/d635330dex1015.htm (2017).

10. Arbutus Biopharma Corporation. Annual report. https://www sec.gov/Archives/edgar/data/1447028/000162828018003276/ arbutus10k2017.htm (2017).
11. CureVac. Registration form F-1. https://www.sec.gov/Archives/ edgar/data/1809122/000110465920086354/tm2016252-11_f1.htm (2020).

12. Silbersher, Z. Does Moderna Therapeutics' pipeline depend upon its patent dispute with Arbutus Biopharma over mRNA delivery? Markman Advisors https://www.markmanadvisors.com/ blog/2018/12/17/does-moderna-therapeutics-pipeline-dependupon-its-patent-dispute-with-arbutus-biopharma-over-mrnadelivery (2018).

13. Arbutus Biopharma Corporation. Form 8-K. https://www.sec.gov/ Archives/edgar/data/1447028/000117184318002661/f8k_041218. htm (2018).

14. BioNTech and Genevant. License and co-development agreement. EX-10.17. https://www.sec.gov/Archives/edgar/data/ 1776985/000119312519241112/d635330dex1017.htm (2018).

15. Pfizer \& BioNTech. Research collaboration and license agreement. EX-10.18. https://www.sec.gov/Archives/edgar/data/ 1776985/000119312519241112/d635330dex1018.htm (2018).

16. BioNTech. Registration form F-1. https://www.sec.gov/Archives/ edgar/data/1776985/000119312520195911/d939702df1.htm (2020).

17. Herman, B. The NIH claims joint ownership of Moderna's coronavirus vaccine. Axios https://www.axios.com/modernanih-coronavirus-vaccine-ownership-agreements-22051c422dee-4b19-938d-099afd71f6a0.html (2020).

18. Rizvi, Z. The NIH vaccine. Public Citizen https://www.citizen.org/ article/the-nih-vaccine/ (2020).

19. Rizvi, Z. Leading COVID-19 vaccine candidates depend on NIH technology. Public Citizen https://www.citizen.org/article/ leading-covid-19-vaccines-depend-on-nih-technology/ (2020).

20. Gaviria, M. \& Kilic, B. mRNA-1273 vaccine patent landscape (for NIH-Moderna vaccine). Public Citizen https://www.citizen.org/ article/modernas-mrna-1273-vaccine-patent-landscape/ (2020).

21. Gaviria, M. \& Kilic, B. BioNTech and Pfizer's BNT162 vaccine patent landscape. Public Citizen https://www.citizen.org/article/ biontech-and-pfizers-bnt162-vaccine-patent-landscape/ (2020).

22. van Eck, N. J. \& Waltman, L. VOSViewer: visualizing scientific landscapes. https://www.vosviewer.com (2010).

23. Bastian, M., Heymann, S. \& Jacomy, M. Gephi: an open source software for exploring and manipulating networks. Int. AAAI Conf. Weblogs and Social Media https://gephi.org/publications/ gephi-bastian-feb09.pdf(2009).

Competing interests

The authors declare no competing interests.

\section{Additional information}

Supplementary information The online version contains supplementary material available at https://doi.org/ 10.1038/s41587-021-00912-9. 